\title{
SCANNING ELECTRON MICROSCOPIC (SEM), HISTOLOGICAL AND MORPHOLOGICAL STUDY OF THE MONGOOSE (Herpestes ichneumon L., 1758) TONGUE IN SOUTH TURKEY
}

\author{
A. Haligur ${ }^{1}$, S. Ozkadif ${ }^{*}$, A. Alan ${ }^{2}$ and Y. Yener ${ }^{3}$ \\ ${ }^{1}$ Cukurova University, Ceyhan Veterinary Medicine, Department of Anatomy, Adana, Turkey \\ ${ }^{2}$ Erciyes University, Veterinary Medicine, Department of Anatomy, Kayseri, Turkey \\ ${ }^{3}$ Bolu Abant Izzet Baysal University, Education Faculty, Department of Primary Education, Bolu, Turkey \\ ${ }^{*}$ Corresponding author's Email: semaerten80@gmail.com
}

\begin{abstract}
This study aimed to investigate the scanning electron microscopic (SEM), histological and morphological characteristics of the tongue and papillae in Egyptian mongoose (Herpestes ichneumon L, 1758). The tongues of two (one female, one male) dead mongoose tongue was used as material. The tongues of the mongooses were removed via the dissection method and morphometric measurements were taken. The tongues were fixed in $10 \%$ buffered formalin solution. Scanning electron microscopy and histological analyses were performed. According to the results, there were four types of papillae; filiform, fungiform, vallate-and foliate. The filiform papillae differed in terms of type and location on the tongue. It was seen that the filiform papillae had an arrow shape in the lateral cuts. The filiform type was observed on the tip of the tongue, both filiform and bound types on the middle of the tongue and both conic and hook types on the root. The foliate papillae were located laterally in the tongues and did not have ducts. There were four vallate papillae in the tongue of the male mongoose and three vallate papillae in that of the female mongoose. This study presents the first SEM, histological and morphological analyses of the tongue and its papillae in the Egyptian mongoose found in Turkey.
\end{abstract}

Key words: Mongoose, papillae, SEM, wild animal.

\section{INTRODUCTION}

The Egyptian mongoose is a species that belongs to the Viverridae family (Kuru, 1999; Demirsoy, 2003). The Egyptian mongoose lives in different geographical regions but is generally found near trees by water in Spain, Portugal, Israel, Italy, Yugoslavia and a vast part of Africa, South Africa) and Turkey (only Adana and Aydın region) (Demirsoy, 1998; Ramsay, 2002; Sobrino et al., 2007; Atay and Yeşiloğlu, 2012). Generally, the diet of the mongoose consists of mice, scorpions, snakes, several invertebrates, fishes, amphibians, reptiles, birds and small mammals. They also feed on various types of fruit (Atay and Yeşiloğlu, 2012).

The tongue is the first surface that food contacts in the oral cavity; thus, it is a very important organ for the digestive system. During the swallowing of the received pieces, in addition to tasting, the tongue has a mechanical function (König and Liebich, 2014). The protrusion of the dorsum of the tongue is the generic name given to the local changes in the tongue mucosa (Dursun, 2010) and the anatomical structures as the papillae linguae on the tongue, which are considered as the first part of the digestive system, are referred to as lingual papillae (König and Liebich, 2014). Lingual papillae are classified into two groups according to their functional and anatomic properties. The first group has the taste function whereas the second group has a mechanical function (Nickel et al., 1986; König and Liebich, 2014). Taste papillae (papillae gustatoriae) consist of fungiform, vallate and foliate papillae while and mechanical papillae are classified as filiform, lentiform and conic (Getty, 1975; Nickel et al., 1986; Dursun, 2010).

There are many studies concerning the tongues of different animals in the literature, including those on cats (Sarma et al., 2009), fox (Jackowiak and Godynicki, 2004), pig (Atalar and Karan, 2011; Karan et al., 2011), mouse (Toprak, 2006), bear and panther (Emura et al., 2001), dog (Emura et al., 2000), deer (Erdogan and Perez, 2014), mongoose (Herpestes edwardsi) (Iwasaki and Miyata, 1989) and Herpestes ichneumon living in Eygpt (Selim and Samir, 2018). The aim of this study was to determine the possible histological, SEM or morphological changes in the tongue of the Egyptian mongoose (Herpestes ichneumon L., 1758) found in Turkey in suitable ecological conditions for this species that originates from Africa.

\section{MATERIALS AND METHODS}

In this study, two dead mongooses [one female $(6.34 \mathrm{~kg})$ and one male $(5.72 \mathrm{~kg})]$ were used. This study was performed with the permission of the General Directorate of Nature Conservation and National Parks of 
the Ministry of Forestry and Water Affairs (Permission number: 38002405-445.05-177733). After removing the tongue from the mouth, morphometric measurements were taken by using a digital caliper. The tongue was kept in $10 \%$ formalin until scanning electron microscopic (SEM) and histological analyses.

SEM procedure: The tissues of the tongues were washed twice using $0.1 \mathrm{M}(\mathrm{pH} 7.4)$ phosphate buffer solution and then were kept in $2.5 \%$ glutaraldehyde solution for two days. After that period, the tissues were keptin $1 \%$ osmiumtetroxide $\left(\mathrm{OsO}_{4}\right)$ for one hour. Then, they were passed through a sequential series of aseton and dried using a critical point dryer. They were coated with gold using a Polaron SC7620 sputter coater and finally the images were taken using LEICA LEO 440 trade SEM at various magnifications.

Histological procedure: After the tongue of the mongooses were cleaned with phosphate buffer solution and histologically examined under a microscope, the appropriate sections of the tongue were fixed in $10 \%$ formaldehyde for 24 hours in order to preserve the tissue structure in the nearest living state and obtain thin sections by increasing hardness. The tissue samples were washed with water to for remove formaldehyde and passed through a series of low to high alcohol grades to remove the water. After paraffin embedding, the blocks were transversely cut into $5 \mu \mathrm{m}$ sections and stained with hematoxylin-eosin (H\&E) and Masson's trichrome stain for a general histological examination. After staining, the samples were dehydrated by passing through alcohol series, cleared with xylene and mounted with Entellan (Merck, Darmstadt/Germany). The slides were examined histologically under a light microscope (Olympus BX51, Japan) and photographed using an with Olympus DP70 digital camera.

\section{RESULTS}

Morphological findings: The tongues of the mongoose were elongated with an oval flat apex (Fig. 1). It was seen that the base of the oral cavity was connected with the frenulum of the tongue. The tongues were examined at three areas; at tip, middle and root. After dissection morphometric measurements were obtained, which are presented in Figures 2 and 3.

SEM findings: The SEM findings of the tongues revealed the presence of filiform, fungiform, foliate, vallate, conic and hook shape-like papillae on the tongues. The examination of the SEM images belonging to both mongooses showed that the filiform papillae on the dorsal face of the tongues (Fig.4-1, 2, 3/ F) had an arrow-shaped distribution and tips of the filiform papillae were through caudal. The ultrastructures of these papillae were typical in the different regions of the tongue. At the tip of the tongue in the midline, the shape of filiform papillae was changed to a round bar structure. The papillae had a blind ending (Fig.4-1, 2/B), fewer in number, more prominent and longer compared to the other parts. In addition, these papillae were seen to be corneous and have a fibriform shape. However, on the lateral surface of the tip and middle regions of the tongue, the shape of these papillae these were similar to an arrow (Fig. 4- 1,3/F) and they were more intensely observed.

Fungiform papillae (Fig.4-3, 4/FU) were found scattered between the filiform papillae and they had an round shape. Each fungiform was surrounded by an evident groove. These papillae were mostly located between the filiform papillae after the tip $1 / 3$ of the bilateral tongue tip. It was noticed that the fungiform papillae were intense between the filiform papillae. These papillae were not seen at the front end of the tongue.

Foliate papillae (Fig.5-1, 2/Fl) were found to have three leaves parallel to each other, on the bilateral edge of the tongue. The taste pores were not observed on these papillae.

Vallate papillae (Fig.6-V) were extensively found on the dorsal aspect of the middle and end of the tongue. Their distribution was similar to a "v" shape. Four vallate papillae were found in the male mongoose and three vallate papillae in the female mongoose (two on the right and one on the left). This shape of vallate papillae was characterized by a mushroom-shaped protrusion and a deep ditch. These papillae were completely surrounded by the circumpapillary sulcus.

At the end of tongue, some of the papillae were observed to have a conical shape and pointed hooks (Fig.7-H). These hook and conic shaped papillae were numerically reduced when they approached the epiglottis. It was determined that these papillae had a wide base and the ends with an irregular structure of the hook were extended in different directions.

Histological findings: Under light microscopy, the ventral surface of the examined tongue mucosa was surrounded by the keratinized squamous epithelium (Fig. 8 ). Beneath this epithelium was the lamina propria layer with abundant collagen fibrils and the lingual musculature beneath it (Fig. 9). The connective tissue layers and collagen fibrils in the submucosa of the lamina propria became more prominent after Masson's trichrome staining (Fig. 10). Different types of papillae were seen as small protrusions located close to each other on the postero-lateral surface of the dorsal side of the tongue (Fig. 10). Among these papillae, the filiform type appeared as small and conical. These papillae have a mechanical role because they do not contain taste buds. In fungiform papillae, especially the keratinized multilayered squamous (flattened) epithelium was evident. In the lamina propria region, there were rich vascular and collagen networks and bundles of muscle 
fibers beneath similar to the previous reports on other species.

On the ventral surface of the tongue, between the bundles of muscle fibers, some structures were seen to be similar to serous and mucous glands (Figs. 11-A, B). These structures were not like the gland epithelium due to their morphological structure, but they were shaped as fatty tissue islands that resembled unilocular fat cells.

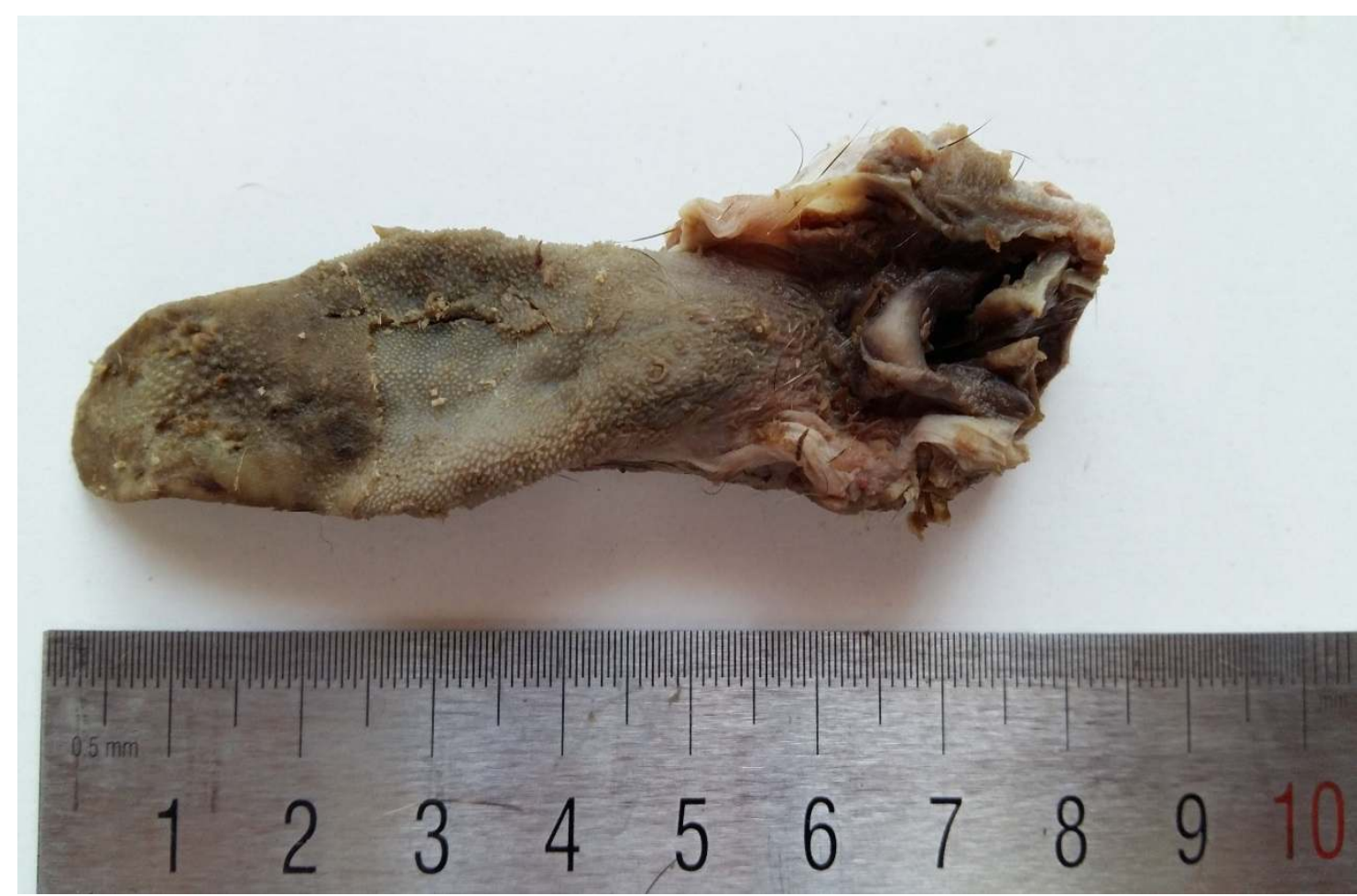

Figure 1. The general appearance of the dorsal surface of mongoose tongue.

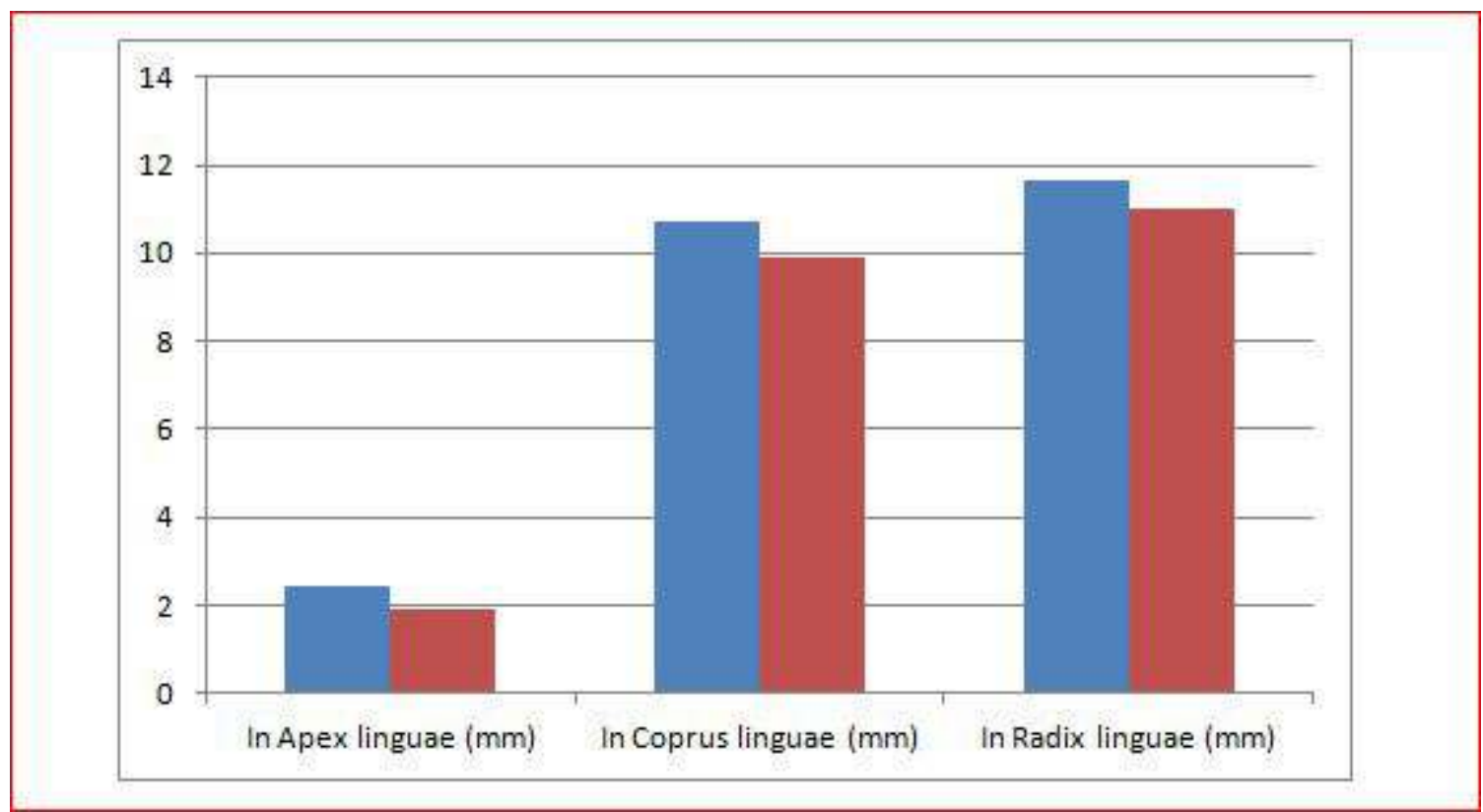

Figure 2. The tongue measurements in different regions showed differences in the female and the male mongoose. This configuration was made to different part to thickness of tongues. blue: male, red: female. 


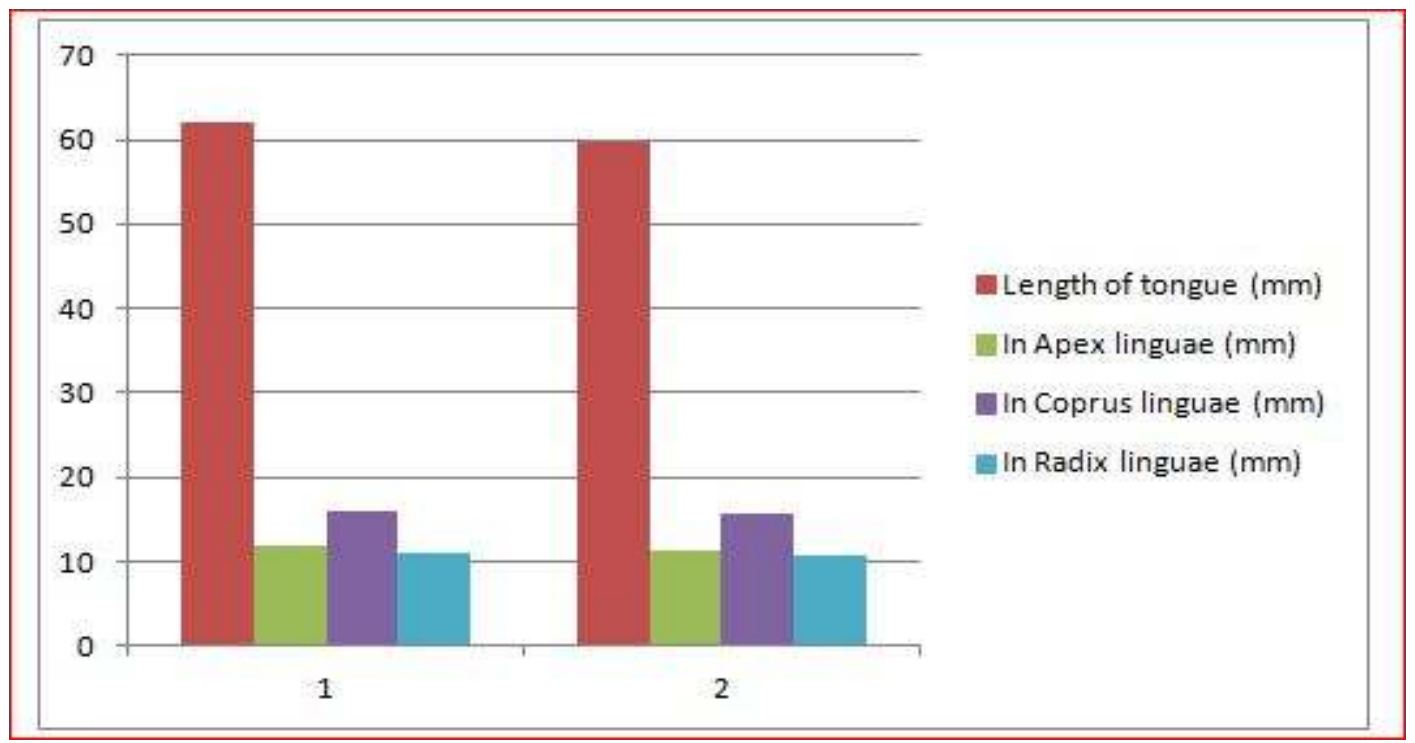

Figure 3. The tongue measurements in different regions showed differences in the female and the male. 1: male mongoose, 2: female mongoose, blue: Weight of mongooses, red: length of the tongue, green: tip length of the tongue, purple: middle length of tongue, blue: radix linguae.
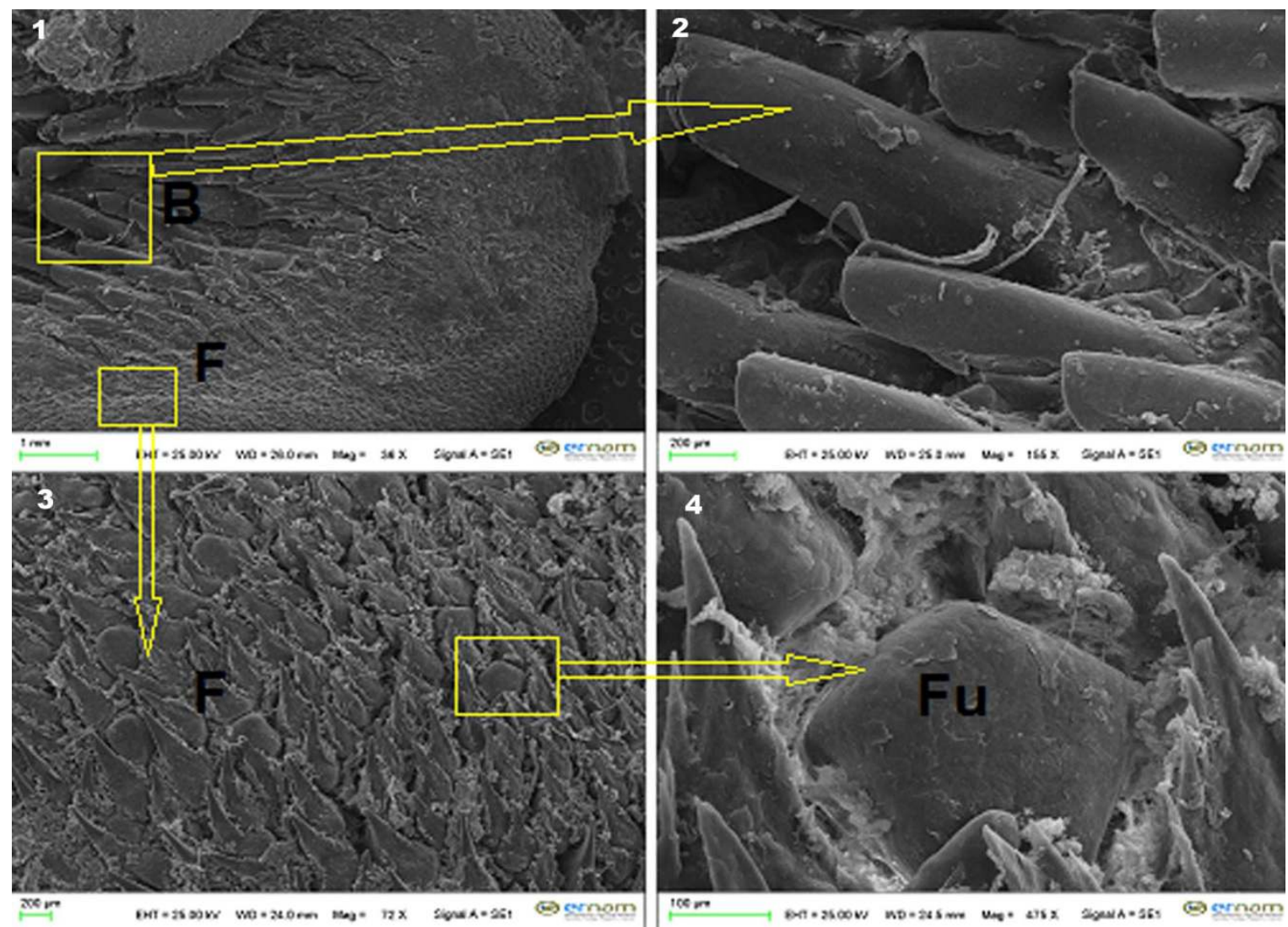

Figure 4. The tip of tongue and general appearance of the dorsal surface papillae. Localization of the fungiform papillae and scattered within the filiform papillae F: Filiform papilla, B: Blind papilla on the tip, FU: Fungiform papilla. 1: Tip of tongue. SEM magnification 36X and scale bars 1 mm, 2: Magnification of 1. SEM magnification 155X and scale bars $200 \mu \mathrm{m}, 3$ : Filiform papillae on the lateral surface of the tongue in mongoose, SEM magnification 72X, Scale bars: $200 \mu \mathrm{m}$, 4: Magnification of 3. SEM magnification 475X, Scale bars: $100 \mu \mathrm{m}$. 

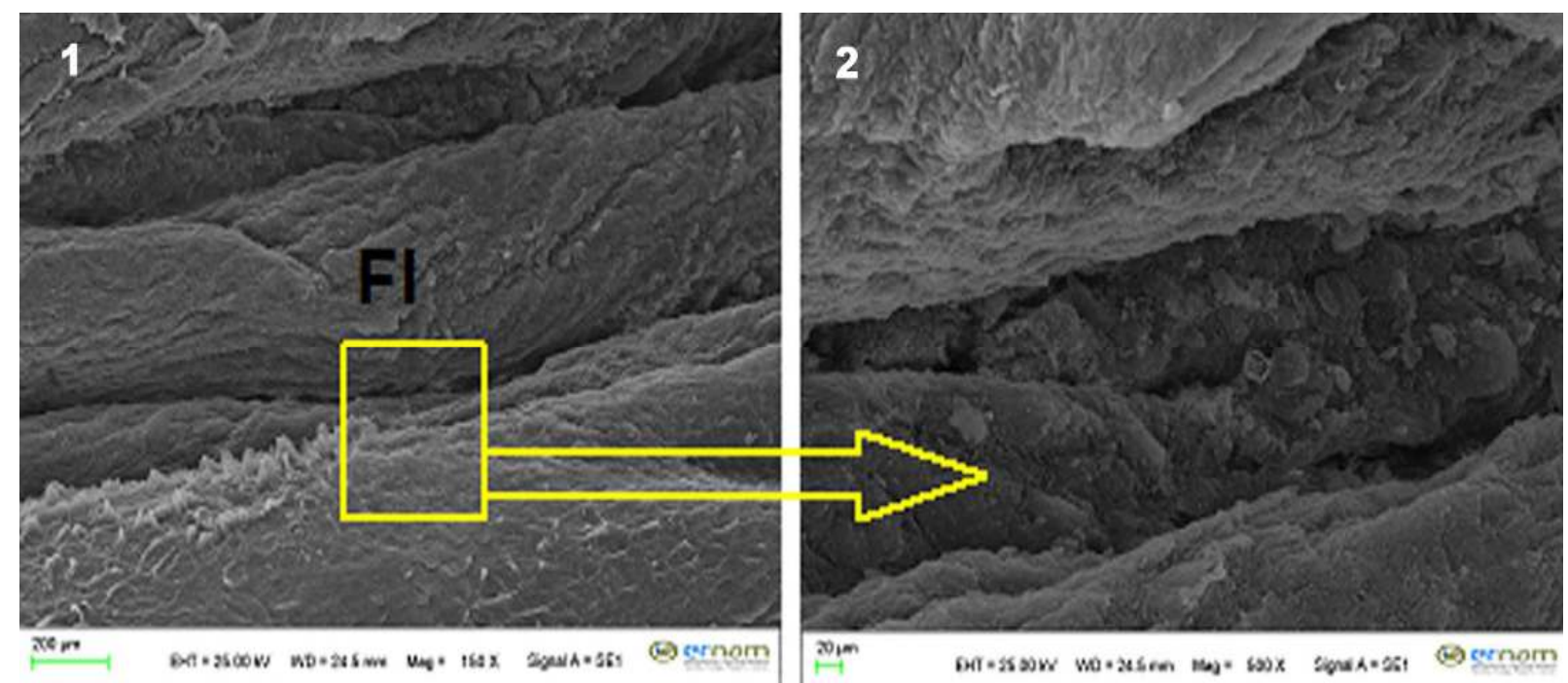

Figure 5. The lateral edge and end of tongue. Fl: Foliate papillae. 1: The appearance of foliate papillae. SEM magnification 150X, Scale bars: $200 \mu \mathrm{m}$, 2: Magnification of 1. SEM magnification 500X, Scale bars: 20 $\mu \mathrm{m}$.

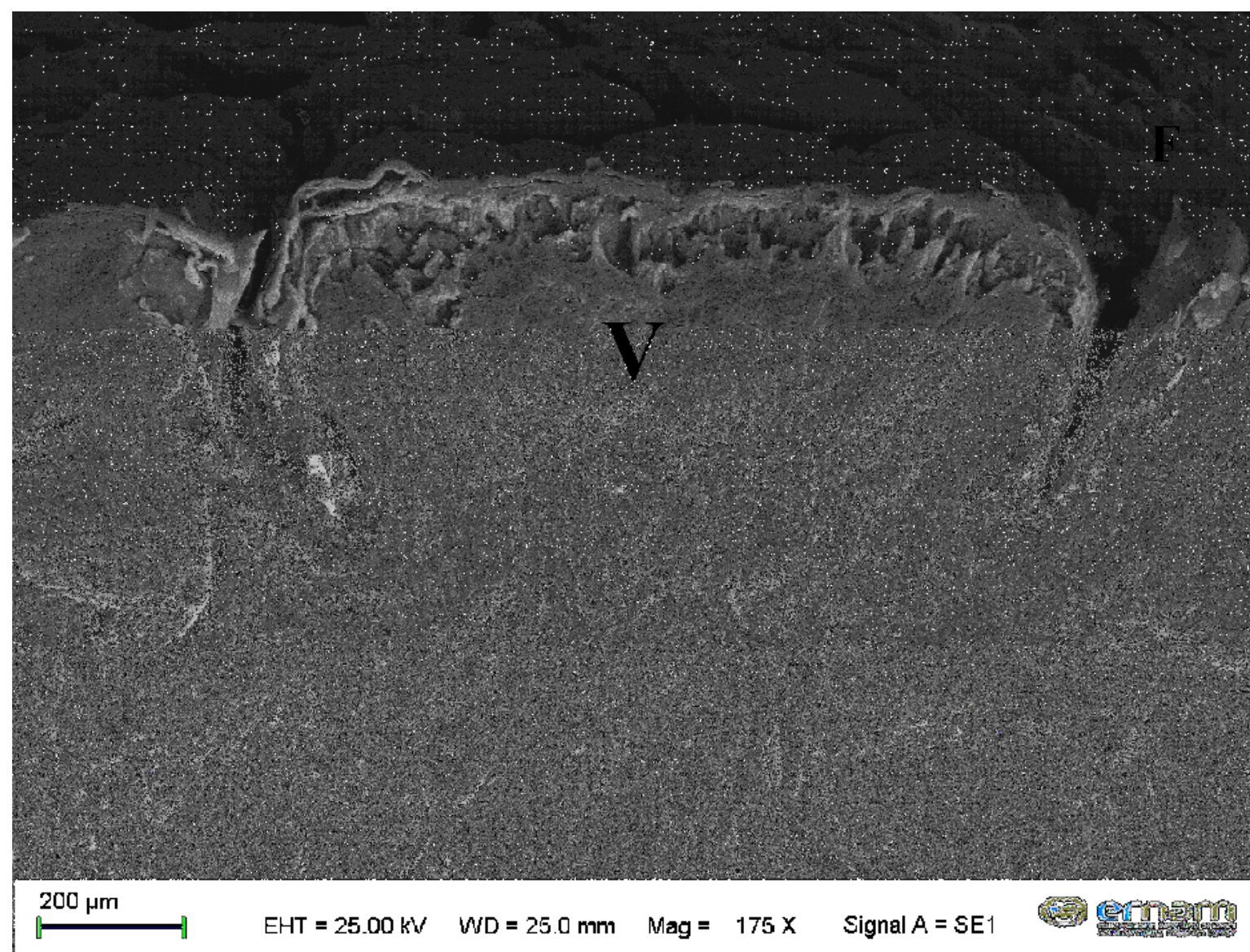

Figure 6. View of transversal section of the vallate papilla. V: Vallate papilla. SEM magnification 175X, Scale bars: $200 \mu \mathrm{m}$. 


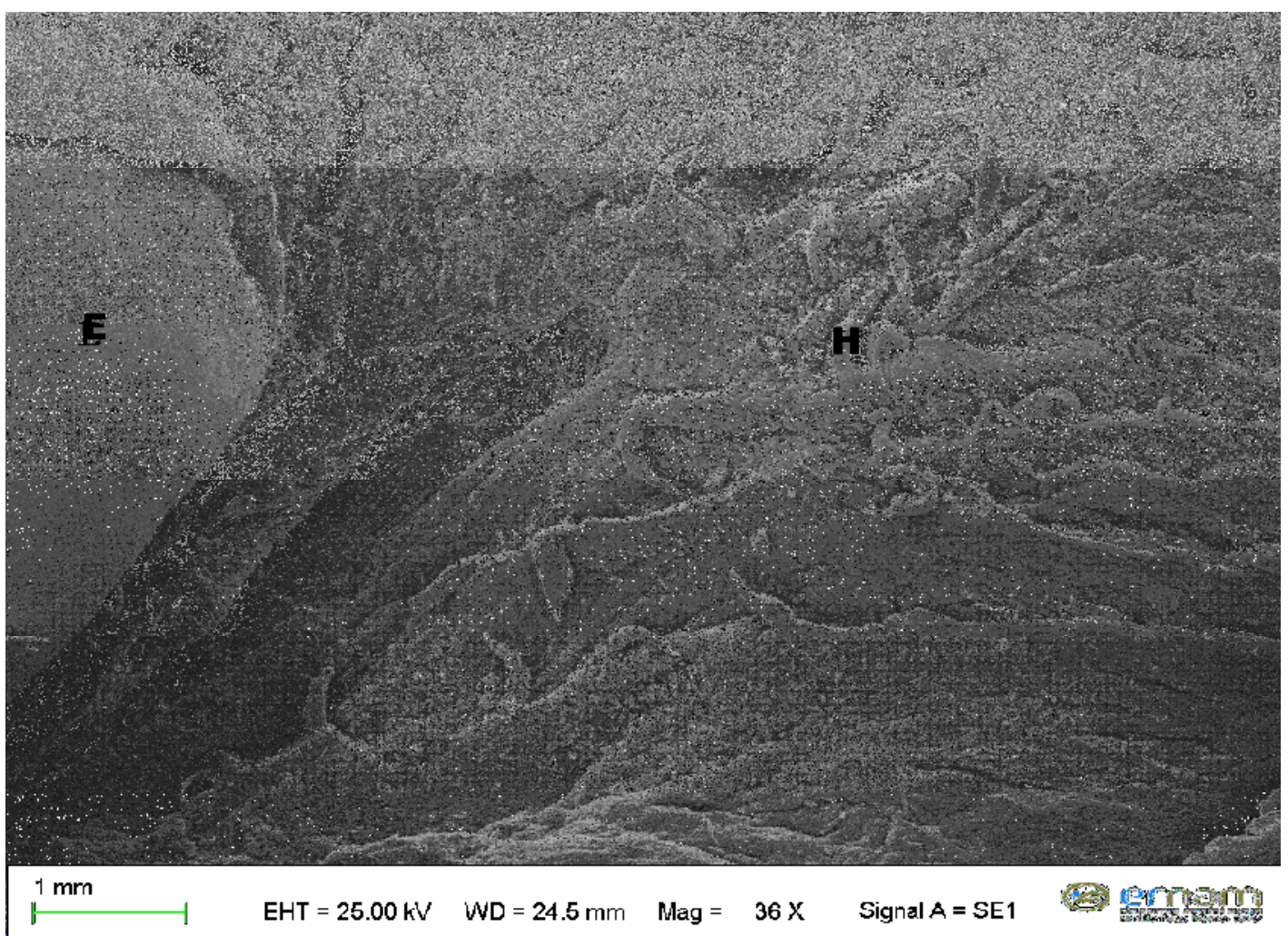

Figure 7. Root of the tongue. 1: The appearance of hook shape papillae. E: Epiglottis, H: Hook shape papillae. SEM magnification 36X, Scale bars: $1 \mathrm{~mm}$.

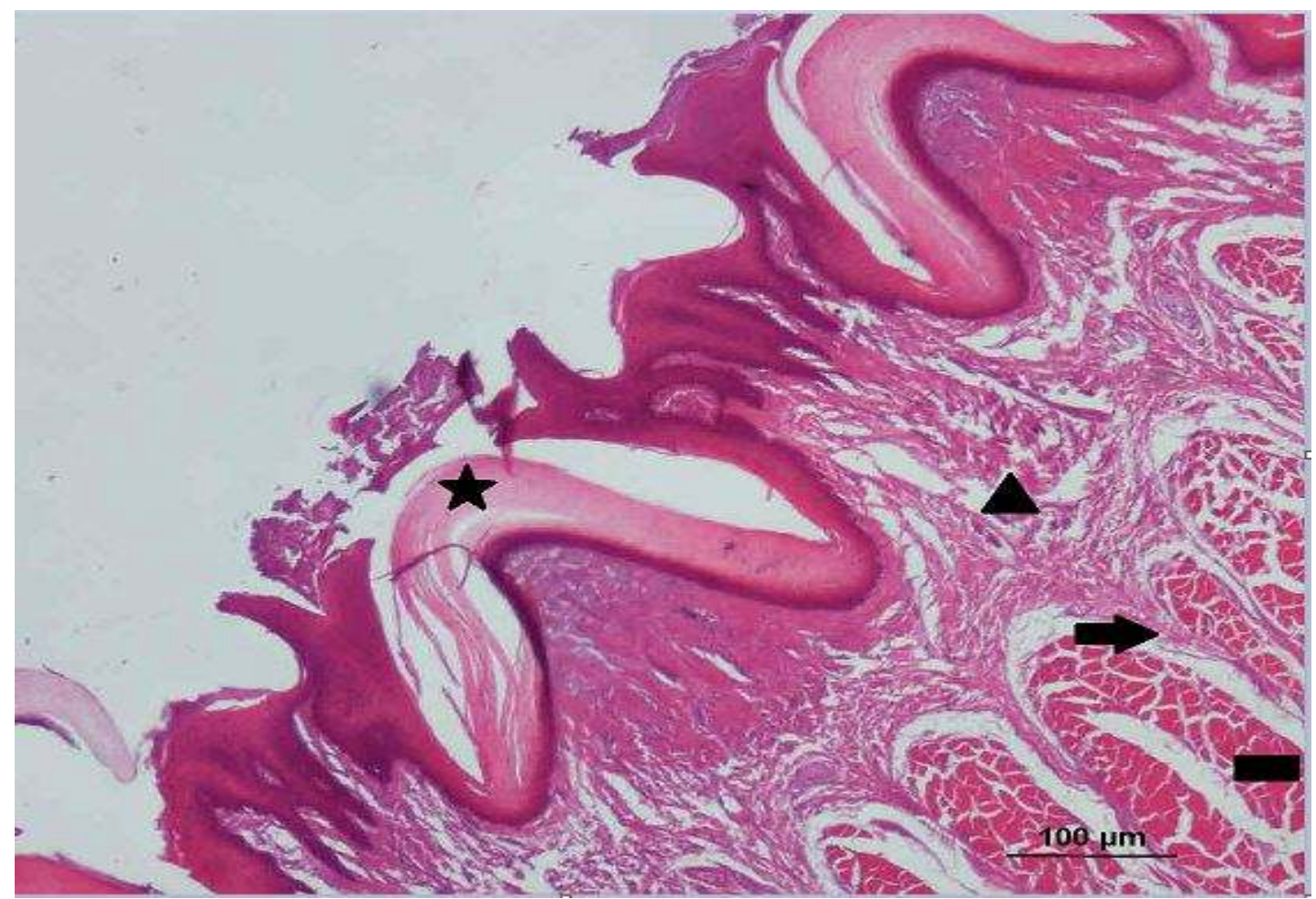

Figure 8. Tongue mucosa layers in transversal section of the ventral surface. Stratum corneum layer (star), other sublayers of lamina epithelium (triangle), lamina propria (arrow) and tunica muscularis (skeletal muscle layer) (rectangle) where collagen fibers are abundant. $H \& E$, x10. 


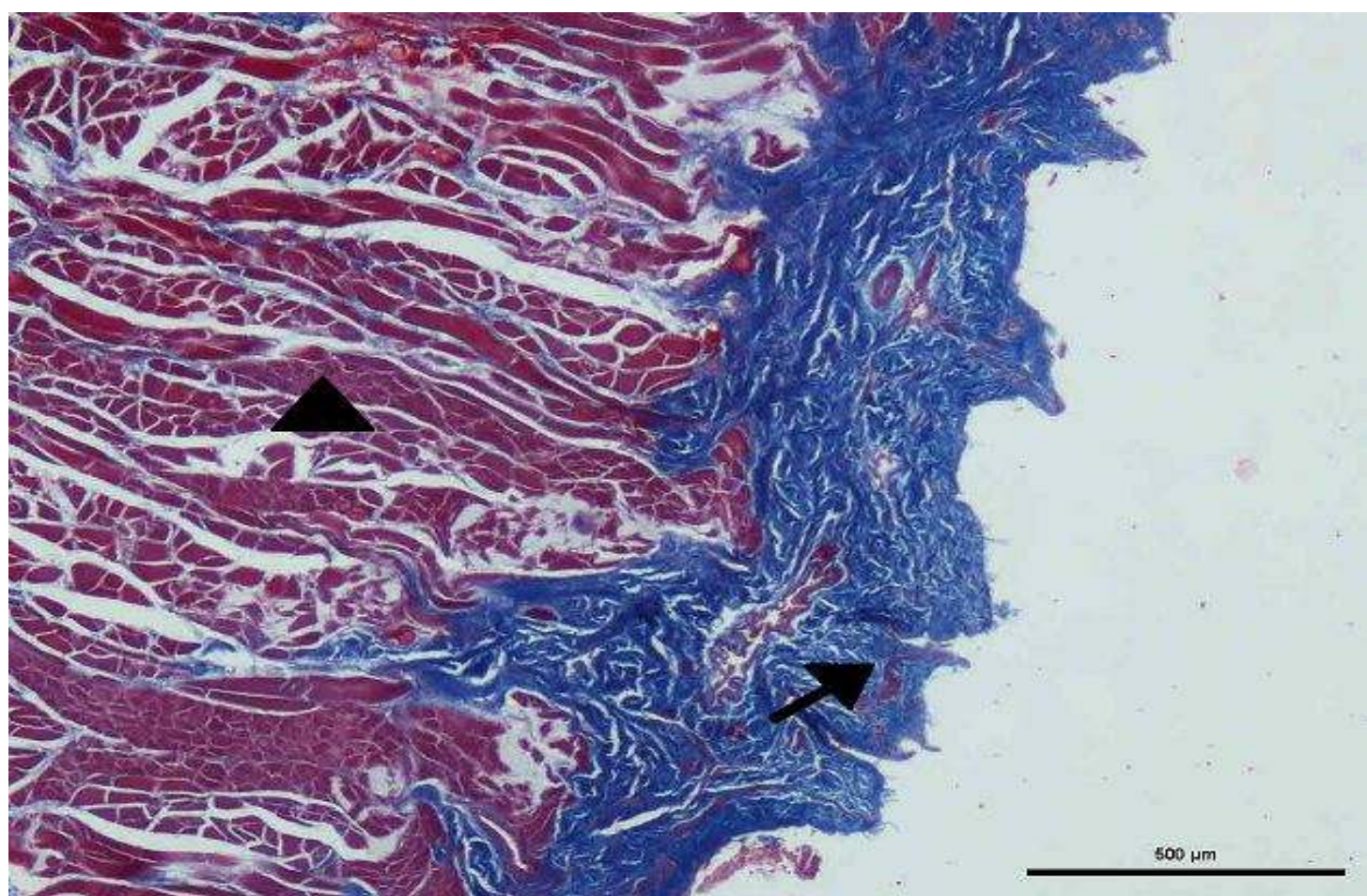

Figure 9. Lamina propria layer on the ventral side of the tongue. Collagen fibers (arrow) on the lamina propriasubmucosa and bundles of muscle fibers (arrowhead) under this region. Masson's trichrome, $x 4$.

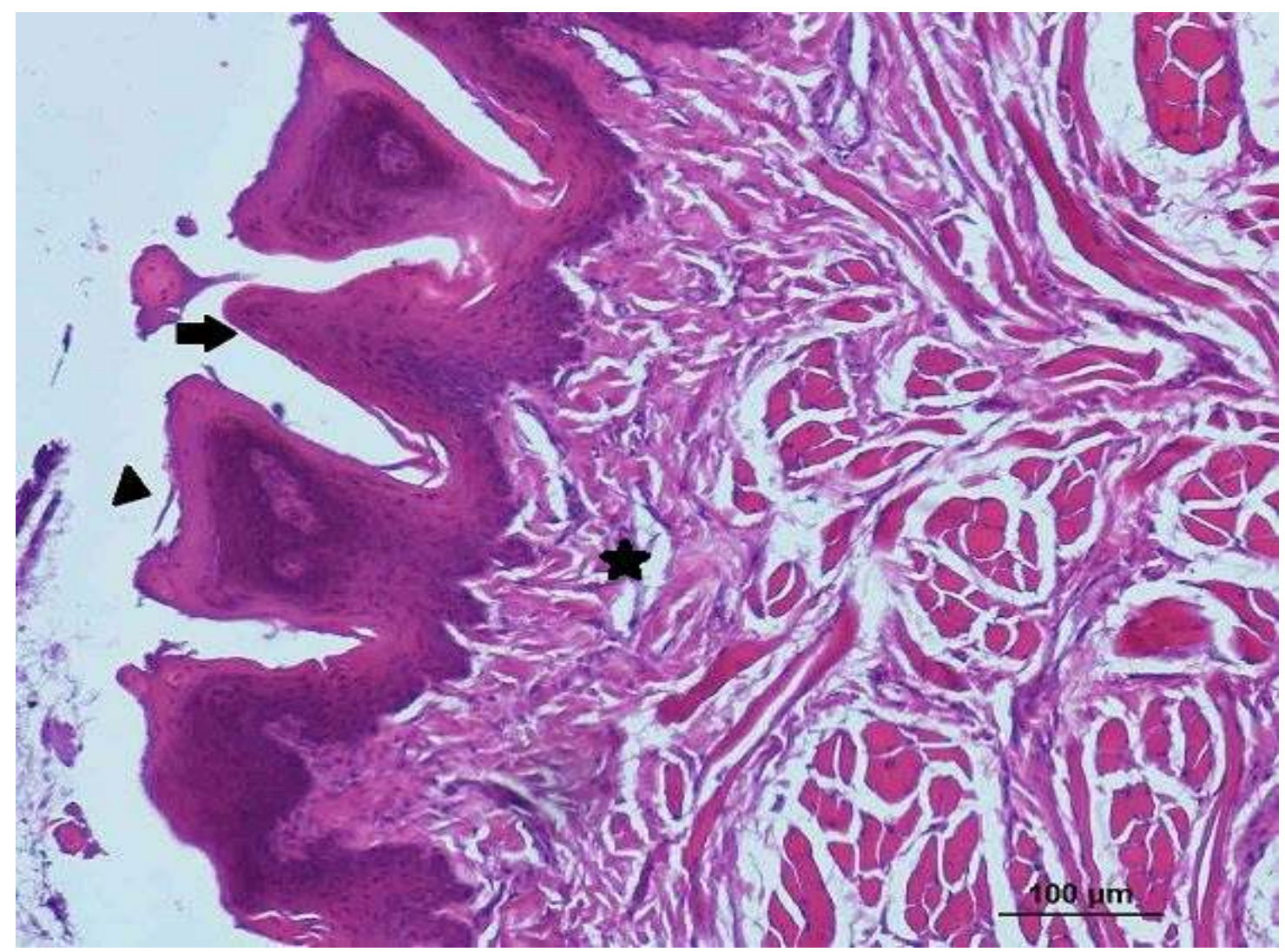

Figure 10. Transversal section of the dorsal surface of the tongue. Fungiform papillae (arrowhead), conical papillae (arrow) and lamina propria-submucosa (star), H\&E, x10 


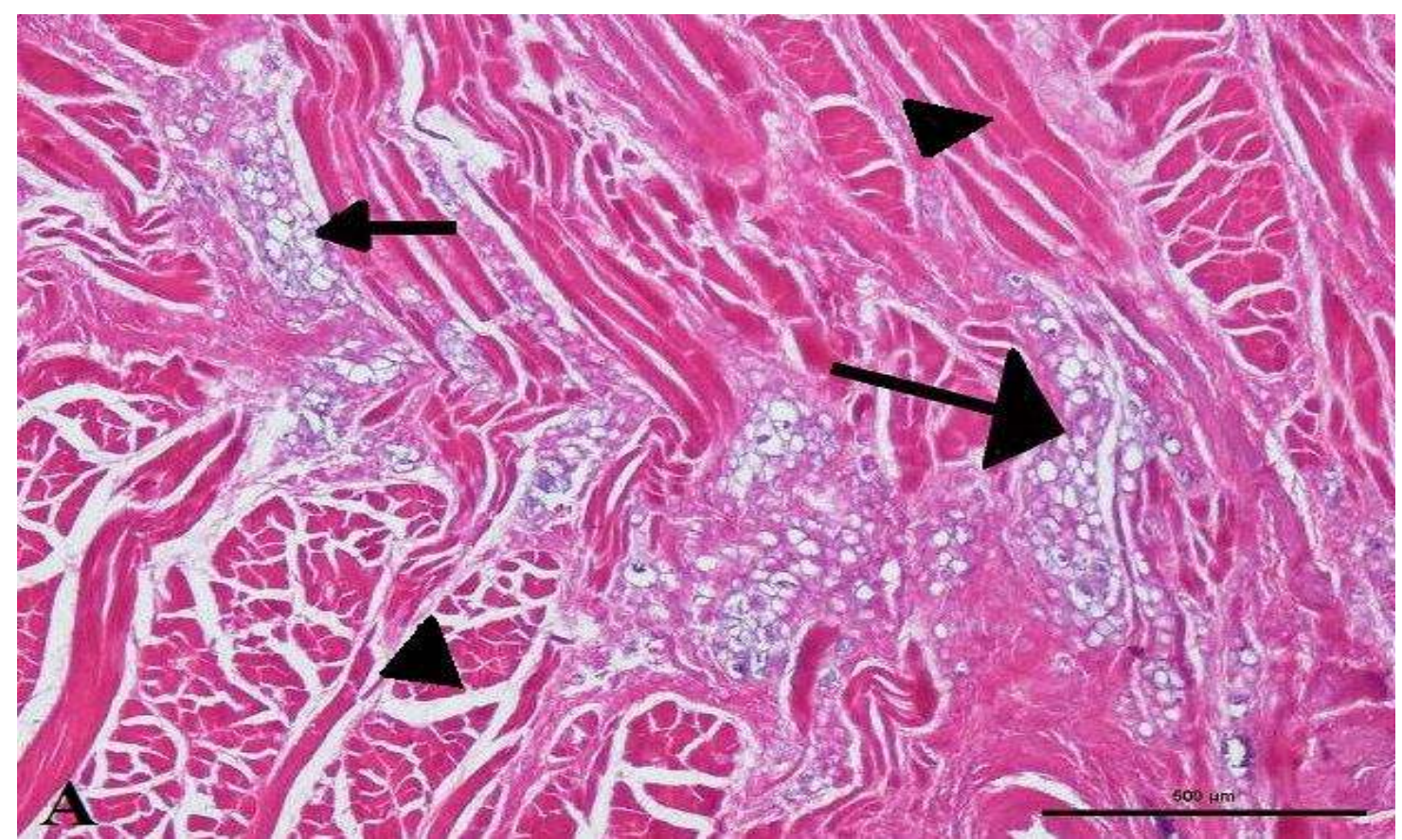

Figure 11. A: Fatty tissue islands (arrows) formed by unilocular fat cells located between skeletal muscle fiber bundles (arrowheads), x4. B: Higher magnification of the same region, $H \& E$, x20

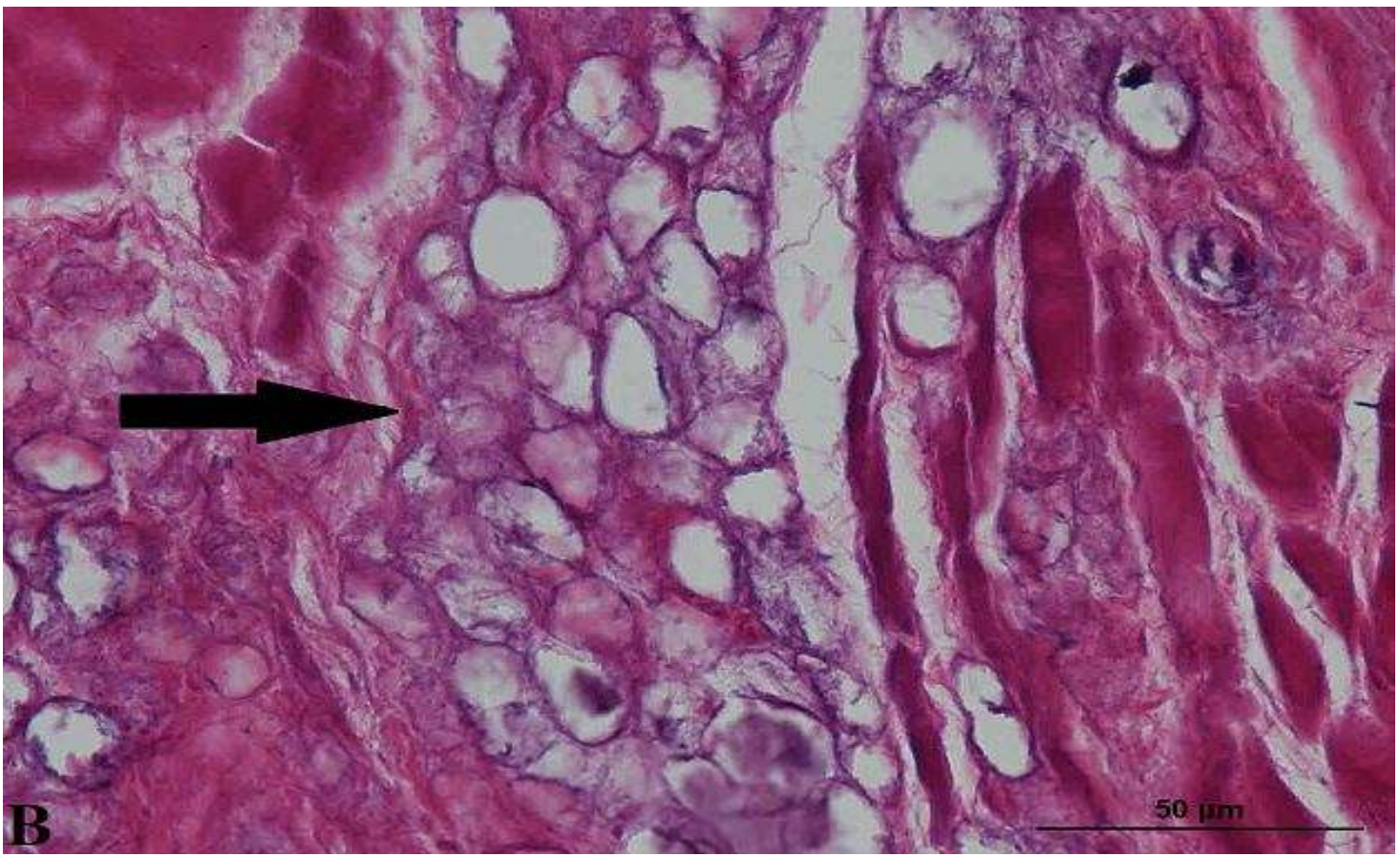

Figure 11. B: Higher magnification of the same region, $H \& E$, x20.

\section{DISCUSSION}

The tongue shape and their structures vary according to the oral function (nutrition, food intake, mastication, etc.). Mongooses are well-known for fighting and killing snakes (even poisonous varieties as cobras and pit vipers) for prey. Since their diets cover insects and mammals of different sizes (Atay and Yeşiloğlu, 2012), their tongue and the related structures morphologically differ from those of other carnivores.

In different animal species, the length of the tongue was reported to be 4 to $5 \mathrm{~cm}$ for dogs (Getty, 1975), 7-8 cm for foxes (Jackowiak and Godynicki, 2004) and 6-7 cm for pigs (Atalar and Karan, 2011; 
Karan et al., 2011). In this study, the length and shape of the mongoose tongue measured different from those of the mongoose found in Egypt. This length of the tongue $61.97 \mathrm{~mm}$ for the male and $59.71 \mathrm{~mm}$ for the female mongoose, which are twice the tongue length of the mongooses in the Egypt (Selim and Samir, 2018). Furthermore, in contrast to the thick apex and lateral edges of the tongue body of the mongoose living in Egypt (Selim and Samir, 2018), in this study, these structures were thin and as similar to those of the cat tongue (Sarma et al., 2009). As indicated by the findings of this study, the length of the tongue depends on the size of the animals.

In foxes and Carnivora, the filiform papillae are found on the posterior part and the dorsal surface of the tongue from apex linguae to the radix linguae (Jackowiak and Godynicki, 2004; Iwasaki and Miyata, 1989; Emura et al., 2000). In a study carried out on South American camelids, these papillae were located on the median channel of dorsal surface of the tongue and shaped like a hook (Erdogan et al., 2016). In another study on the Merino sheep, filiform papillae were found from the apex to the corpus of the tongue but rarely observed in the lateral region. Moreover, these papillae are seen to have different types (primary and secondary) (Can et al., 2016). For example, filiform papillae are only located on the lateral region of the deer tongue (Erdogan and Perez, 2014). In studies conducted with mice (Toprak, 2006) and blind mice (Yoshimura et al., 2013), it is indicated that filiform papillae are located in three different areas on the tongue with three different shapes while they are reported to have two different shapes in pigs (flat or cylindrical) (Toprak, 2006; Karan et al., 2011). In the current study carried out with mongooses, the filiform papillae were observed on the whole surface of the tongue (mostly at the tip and middle of the tongue). According to their shape, four different types were identified: The first type of filiform papillae were to corneous with a fibriform shape and located at the tip of the tongue while the remaining three types were similar to be like to the shape of the papillae examined in other animals. Furthermore, the histological examination of the filiform papillae revealed that they had a conical shape and generally had small protrusions. In terms of type and location, these papillae were similar to the meerkat, ferret and fox tongue (Emura et al. 2006; Erdoğan et al. 2016). Another finding related to the filiform papillae was the detection of keratinized areas in these papillae, which is in agreement with the finding obtained Selim and Samir (2018), who investigated the features of the tongue in the same species. The last type of papillae in this study had a hook shape, which is different from the literature on the mongoose.

In the silver fox, 12 fungiform papillae were found on the tongue located between filiform papillae. In contrast to the study by Selim and Samir (2018), who reported that the fungiform papillae were located at the posterior part of the tongue, in this study, these papillae were found on the lateral sides of the tongue. They also indicated that the fungiform papillae in this area might contribute to the taste function of the tongue. The shape of the fungiform papillae was flat on the upper surface (Jackowiak and Godynicki, 2004). These papillae are reported to be located on the dorsal face of the tongue and have a crater-like shape in the Merino sheep. (Can et al., 2016). In another study performed with deer, fungiform papillae were seen to have a sphere shape and located on the $2 / 3$ of apex of the tongue and on both lateral dorsal aspects (Erdogan and Perez, 2014). In squirrels face of tongue these papillae are settled on the apex and the lateral region of the tongue and resemble a mushroom-like shape (Unsaldi, 2010). In this study, different from the literature (Jackowiak and Godynicki, 2004; Can et al., 2016; Erdogan and Perez, 2014; Unsaldi, 2010), fungiform papillae were found to have a round shape, and intensely located after the middle $1 / 3$ of the -mongoose tongue bilaterally.

Previous studies reported two foliate papillae in cat (Sarma et al., 2009), and 4-5 laminas in foxes (Jackowiak and Godynicki, 2004). In the current study carried out with mongooses, the foliate papillae had the same localization as reported in the literature (Sarma et al., 2009; Jackowiak and Godynicki, 2004). The number of foliate papillae in the mongooses were not similar the relevant literature (Jackowiak and Godynicki, 2004; Sarma et al., 2009). Moreover, Selim and Samir (2018) referred to the lack of foliate papillae in their study on the same species. However, in our study, we found three foliate papillae in the mongooses we examined and these papillae did not have any taste pores.

Vallate papillae are " $\mathrm{v}$ "- shaped and the number of these papillae is reported as four in foxes (Jackowiak and Godynicki, 2004), six in cats (Sarma et al., 2009) and 28 in pigs (Atalar and Karan, 2011). In the present study, four vallate papillae were identified in the male mongoose but the female only had three vallate papillae.

The literature (Getty, 1975; König and Liebich, 2014), contains studies reporting the presence of conical papillae distributed widely on the dorsal aspect of the cat tongue. Conical filiform papillae in the radix linguae have been shown to extended up to entrance of the pharynx (Iwasaki and Sakata 1989; Emura et al., 2000; Jackowiak and Godynicki, 2004). In this study, some papillae were seen to have conical and pointed hooks shapes but they were reduced in number when they approached the epiglottis.

Conclusions: In this study, different types of lingual papillae on all of the surface of the mongoose tongue were described at (SEM) and light microscopy levels. It was observed that the size of the mongoose tongue changed in proportion to the body size. It was also 
determined that the mechanical papillae had different shapes (blunt-ended, conic and hook-like) compared to other animals. Gustatoric papillae were seen as similar to other animals. However, no taste pores duct was found in the foliate papillae. The morphological structure of the mongoose tongue also seems to vary according to the nutrients contained in their diet.

\section{REFERENCES}

Atalar, O. and M. Karan- (2011). The light and scanning electron microskopic structure of papilla vallatae in the porcupine (Hystrix cristata). J. Anim. Vet. Adv. 10: 3069-3073.

Atay, E. and M. Yeşiloğlu- (2012). The Egyptian Mongoose, Herpestes ichneumon L., 1758 (Mammalia: Carnivora: Herpestidae) in Hatay Province Turkey. K.F.B.D. 2: 74-81.

Can, M., Ş.H. Atalgın, S. Ateş, and L. Takçı- (2016). Scanning electron microscopic study on the structure of the lingual papillae of the Karacabey Merino sheep. Eurasian. J. Vet. Sci. 32: 130135.

Demirsoy, A. (2003). Yaşamın Temel Kuralları. Omurgalılar/Amniyota (Sürüngenler, Kuşlar ve Memeliler) Cilt-III/Kısım-II.Meteksan A.Ş. Ankara. 766 p.

Dursun, N. (2010). Veteriner Anatomi II. Medisan Yayınevi, Ankara. 25-28 p.

Emura, S., A. Tamada, D. Hayakawa, H. Chen, and S. Shoumuras- (2000). Morphology of the dorsal lingual papillae in the bush dog (Speothos venaticus). Okajimas. Folia. Anat. Jpn. 77: 137141.

Emura, S., D. Hayakawa, H. Chen, and S. Shoumura(2001). Morphology of the dorsal lingual papillae in the newborn panther and Asian black bear. Okajimas. Folia. Anat. Jpn. 78: 173-177.

Emura, S., T. Okumura, H. Chen, and S. Shoumura(2006) Morphology of the lingual papillae in the raccoon dog and fox. Okajimas Folia Anat. Jpn. 83: 73-76.

Erdogan, S. and W. Perez- (2014). Anatomical and scanning electron microscopic studies of the tongue and lingual papillae in the chital deer (Axis axis, Erxleben 1777). Acta. Zoologica. (Stockholm). 95: 484-492.

Erdogan, S., S. Arias, and W. Perez- (2016). Morphofunctional structure of the lingual papillae in three species of South American camelids: Alpaca, Guanaco, and Llama. Microsc. Res. Technique. 79: 61-71.

Erdoğan, S., M. Lima, and W. Perez- (2016). Anatomical and Scanning Electron Microscobic Study of the tongue in the Meerkat (Suricata suricata,
Schreber, 1776). Anat. Histol. Embryol. 45: 5159.

Getty, R. (1975). The Anatomy of the Domestic Animals. I, 5th edn. W.B. Saunders Co., Philadelphia. 1538-1539 p.

Iwasaki, S. and K. Miyata-(1989). Fine structure of the filiform papilla of beagle dog. J. Morphol. 201: 235-242.

Jackowiak, H. and S, Godynicki- (2004). The scanning electron microscopic study of lingual papillae in the silver fox (Vulpes vulpes fulva, Desmarest, 1820). Ann. Anat. 186: 179-183.

Karan, M., S. Yilmaz, and A. Aydin- (2011). Morphology of the filiform lingual papillae in porcupine (Hystrix cristata). Anat. Histol. Embryol. 40: 100-103.

König, H.E., and Liebich, H.G. (2004). Veterinary Anatomy of Domestic Mammals. Schattauer, Stuttgart, New York. 279-283 p.

Kuru, M. (1999). Omurgalı Hayvanlar. Palme Yayıncılık. Ankara. 672 p.

Nickel, R., A. Schummer, and E. Seiferle. (1986). The Viscera Of The Domestic Animals. German Edition. Verlog Paul Parey, Berlin, Hamburg.

Ramsay, S.L. (2002). Decapitation of the tortoise Chersina angulata: is the large grey mongoose a headhunter? Afr. Zool. 37(1): 114-116.

Sarma, K., M. Sarma, and S.N. Kalita- (2009). Gross anatomical and biometrical studies on the tongue of an adult small Indian civet cat. Israel. J. Vet. Med. 64: 36-38.

Selim, A., and R. Samir- (2018). Light and scanning electron microscope studies of the tongue of the Egyptian Mongoose (Herpestes ichneumon). J. Cytol. Histol. 9: 499. doi: 10.4172/21577099.1000499.

Sobrino, R., O. Cabezon, J. Millan, M. Pabon, M.C. Arnal, D.F. Luco, C. Gortazar, J.P. Dubey, and S. Almeria- (2007). Seroprevalence of toxoplasma gondii antibodies in wild carnivores from Spain. Vet. Parasitol. 148:187-192.

Toprak, B. (2006). Light and scanning microscopic structure of filiform papillae in mice. Veterinarski. Arhiv. 76: 555-562.

Unsaldi, E. (2010). Macroscopic and light microscopic structure of fungiform papillae on the tongue of squirrels (Sciurus vulgaris). Kafkas. Univ. Vet. Fak. Derg. 16: 115-118.

Yoshimura, K., J. Shindo, and I. Kageyama- (2013). Comparative morphology of the papillae linguales and their connective tissue cores in the tongue of the greater Japanese shrew-mole, Urotrichus talpoides. Anat. Histol. Embryol. 42: 21-29. 